\title{
FABRICATION OF Cu-BASED SiC COMPOSITES BY SPARK PLASMA SINTERING OF CU-NITRATE COATED SiC POWDERS
}

\begin{abstract}
An optimum route to fabricate the $\mathrm{Cu}$-based $\mathrm{SiC}$ composites with homogeneous microstructure was investigated. Three methods for developing the densified composites with sound interface between $\mathrm{Cu}$ and $\mathrm{SiC}$ were compared on the basis of the resulting microstructures. Starting with three powder mixtures of elemental $\mathrm{Cu}$ and $\mathrm{SiC}$, elemental $\mathrm{Cu}$ and PCS coated $\mathrm{SiC}$ or PCS and $\mathrm{Cu}-$ nitrate coated $\mathrm{SiC}$ was used to obtain $\mathrm{Cu}$-based $\mathrm{SiC}$ composites. $\mathrm{SEM}$ analysis revealed that the composite fabricated by spark plasma sintering using elemental $\mathrm{SiC}$ and $\mathrm{Cu}$ powder mixture showed inhomogeneous microstructure. Conversely, dense microstructure with sound interface was observed in the sintered composites using powder mixture of pre-coated PCS and Cu-nitrate onto SiC. The relationship between powder processing and microstructure was discussed based on the role of coating layer for the wettability

Keywords: $\mathrm{Cu}-\mathrm{SiC}$ composites, $\mathrm{Cu}$-nitrate, Spark plasma sintering, Microstructure
\end{abstract}

\section{Introduction}

$\mathrm{Cu}$ with high thermal conductivity is promising candidate for application in electronic packaging and thermal management materials. However, the application field of this material is limited because of higher coefficient of thermal expansion (CTE) than the Si substrate in electronic packaging [1]. Recently, $\mathrm{Cu}-$ based composites with low CTE dispersoids have become focus for thermal management applications [2-4]. Among the potential dispersoid materials, $\mathrm{SiC}$ can be an attractive candidate due to its low CTE and high thermal conductivity [5,6]. Generally, method for the fabrication of $\mathrm{Cu}$-based $\mathrm{SiC}$ composites involves powder metallurgy process as sintering of $\mathrm{Cu}$ and $\mathrm{SiC}$ powder compact. However, relatively poor thermal properties of $\mathrm{Cu}$-based $\mathrm{SiC}$ composite were usually obtained because of the decomposition of $\mathrm{Si}$ in $\mathrm{SiC}$ and inhomogeneous microstructure by poor wettability between $\mathrm{Cu}$ and $\mathrm{SiC}$ [7]. Therefore, the key to achieving a useful $\mathrm{Cu}$-based $\mathrm{SiC}$ composites for thermal management application is control of the interfacial reaction between $\mathrm{Cu}$ and $\mathrm{SiC}$.

In this study, we attempt to fabricate the $\mathrm{Cu}$ composites dispersed with $\mathrm{SiC}$ particles by means of the spark plasma sintering using polycarbosilane (PCS) and Cu-nitrate coated $\mathrm{SiC}$ powders, in which $\mathrm{PCS}$ and $\mathrm{Cu}$-nitrate were pyrolyzed and hydrogen-reduced for the formation of $\mathrm{SiOC}$ and $\mathrm{Cu}$ coating layer onto $\mathrm{SiC}$ powders, respectively. Moreover, we discuss the effect of the coating on the densification and microstructural characteristics of the sintered composites.

\section{Experimental}

Three different fabrication processes were applied to obtain the powder mixtures. The first one used mixture of ball-milled $\mathrm{SiC}$ with an average size of $20 \mu \mathrm{m}$ and $70 \mathrm{vol} \% \mathrm{Cu}$ metal powder with an average size of $30 \mathrm{~mm}$. In the second process, PCS was used for pre-coating of SiOC onto $\mathrm{SiC}$ powder. Weighted PCS, corresponding to the thickness of about $100 \mathrm{~nm}$ on the $\mathrm{SiC}$ powder, was dissolved in hexane solution and mixed with $\mathrm{SiC}$ powder. The mixtures were cured and pyrolyzed at $1600^{\circ} \mathrm{C}$. Then, $\mathrm{Cu}$ powder was mixed with the pyrolyzed powder and ball-milled for $10 \mathrm{~h}$ with high purity $\mathrm{ZrO}_{2}$ balls. The detailed procedure is described elsewhere [8]. The third one used mixture of PCS-coated $\mathrm{SiC}$ and $\mathrm{Cu}$-nitrate as source material for $\mathrm{Cu}$. The mixtures were initially calcined at $300^{\circ} \mathrm{C}$ in air and hydrogen-reduced at $350^{\circ} \mathrm{C}$ for $1 \mathrm{~h}$ to obtain $\mathrm{Cu}$-coated $\mathrm{SiC}$ powders. Subsequently, $\mathrm{Cu}$ metal powder was mixed with the above-mentioned mixtures by ball milling.

The densification of the powder mixtures was carried out using spark plasma sintering with a heating rate of $100^{\circ} \mathrm{C} / \mathrm{min}$ at $700^{\circ} \mathrm{C}$ for $10 \mathrm{~min}$ in vacuum under an applied pressure of $30 \mathrm{MPa}$. The processed powders and composites were characterized by X-ray diffraction (XRD, D/Max-IIIC, Rigaku Denki Co., Japan) analysis. The microstructure and elemental analysis were observed by scanning electron microscopy (SEM, JSM6700F, JEOL Co., Japan) equipped with an energy dispersive $\mathrm{X}$-ray spectroscopy (EDX).

* GRADUATE SCHOOL OF CONVERGENCE SCIENCE, PUSAN NATIONAL UNIVERSITY, BUSAN 46241, REPUBLIC OF KOREA

** DEPARTMENT OF MATERIALS SCIENCE AND ENGINEERING, SEOUL NATIONAL UNIVERSITY OF SCIENCE AND TECHNOLOGY, SEOUL 01811, REPUBLIC OF KOREA

\# Corresponding author: stoh@seoultech.ac.k 


\section{Results and discussion}

Typical morphologies for the powder mixture and sintered composite are shown in Fig. 1. It is observed from Fig. 1a that rectangular $\mathrm{SiC}$ and spherical $\mathrm{Cu}$ powders mixed by ball milling for $10 \mathrm{~h}$. To densify the powder mixture, spark plasma sintering at $700^{\circ} \mathrm{C}$ for $10 \mathrm{~min}$ was applied. As clearly seen from Fig. 1b, the $\mathrm{SiC}$ particles were mainly distributed in grain boundaries and many pores were observed. This inhomogeneous microstructure may be attributed to poor wettability between $\mathrm{Cu}$ and $\mathrm{SiC}$, as described in the literature [7].

Figure 2 shows SEM micrograph of the sintered composite prepared from the mixture of $\mathrm{Cu}$ and PCS-coated $\mathrm{SiC}$ powders. Compared with the microstructure of Fig. 1b, homogeneous dispersion of $\mathrm{SiC}$ particles and dense microstructure were observed in the sintered composite. This change in microstructure was thought to be due to the improvement of wettability between $\mathrm{SiC}$ and $\mathrm{Cu}$ by PCS coating onto $\mathrm{SiC}$ powders which induced enhanced densification with homogeneous microstructure $[8,9]$.
However, some pores and cracks between $\mathrm{Cu}$ and $\mathrm{SiC}$ particles are still in the sintered composite. Thus, the uniform pre-coating of $\mathrm{Cu}$ on $\mathrm{SiC}$ particles applied to developing the composite with sound interface.

In order to fabricate the $\mathrm{SiC}$ powders with homogeneously coated $\mathrm{Cu}$ particles on their surfaces, the powder mixture of PCS-SiC and $\mathrm{Cu}$-nitrate was calcined at $300^{\circ} \mathrm{C}$ and hydrogenreduced at $350^{\circ} \mathrm{C}$ for $1 \mathrm{~h}$. The diffraction peaks from the calcined powder can be indexed as a-SiC and $\mathrm{CuO}$ phase as shown in Fig. 3a, whereas those form the hydrogen-reduced were composed entirely of a-SiC and $\mathrm{Cu}$ phase (Fig. 3b). This reduction behavior of $\mathrm{CuO}$ coincides with the reported work [10]. Typical SEM image for hydrogen-reduced powder is shown in Fig. 4, in which the $\mathrm{Cu}$ particles appears light and the $\mathrm{SiC}$ grey. It is clearly represented that fine $\mathrm{Cu}$ particles are homogeneously distributed on the surface of $\mathrm{SiC}$ particles. To fabricate $\mathrm{SiC}-70$ vol $\% \mathrm{Cu}$ composites, $\mathrm{Cu}$ metal powder was mixed with the hydrogen-reduced powders and sintered at $700^{\circ} \mathrm{C}$ and $30 \mathrm{MPa}$ by spark plasma sintering.
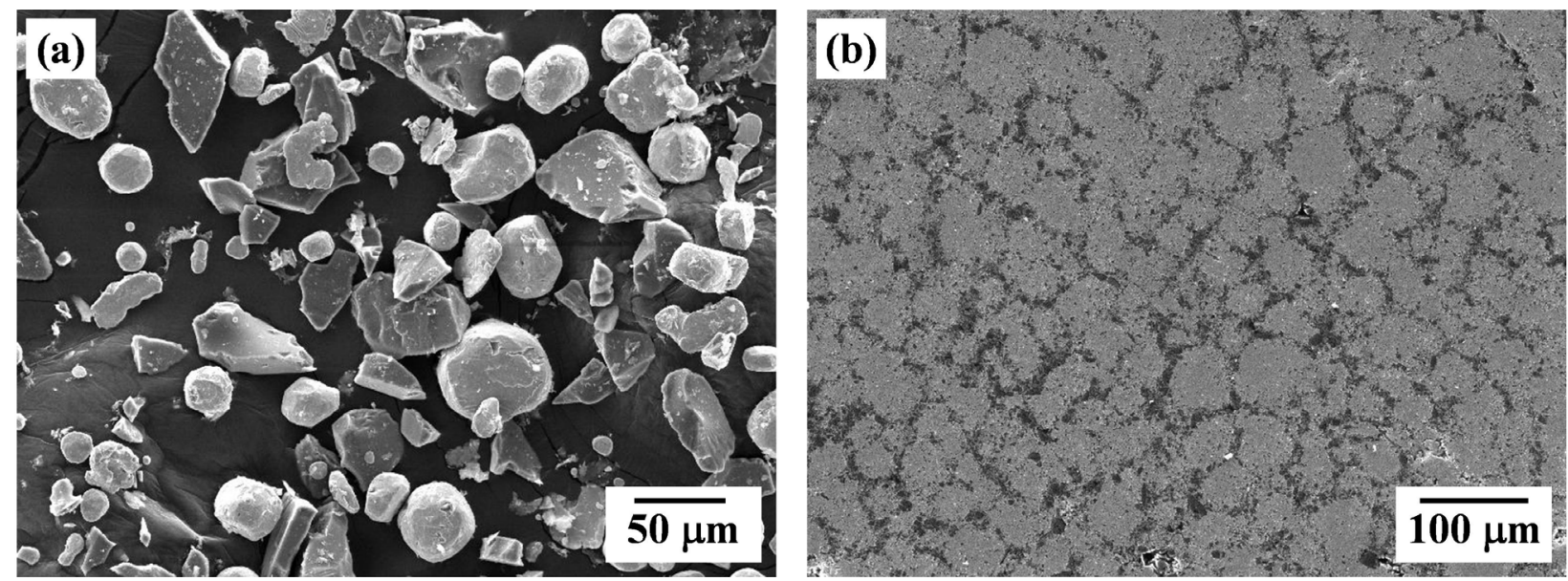

Fig. 1. SEM images of (a) ball-milled powder mixture of elemental $\mathrm{Cu}$ and $\mathrm{SiC}$ and (b) densified composite by spark plasma sintering at $700^{\circ} \mathrm{C}$ for $10 \mathrm{~min}$

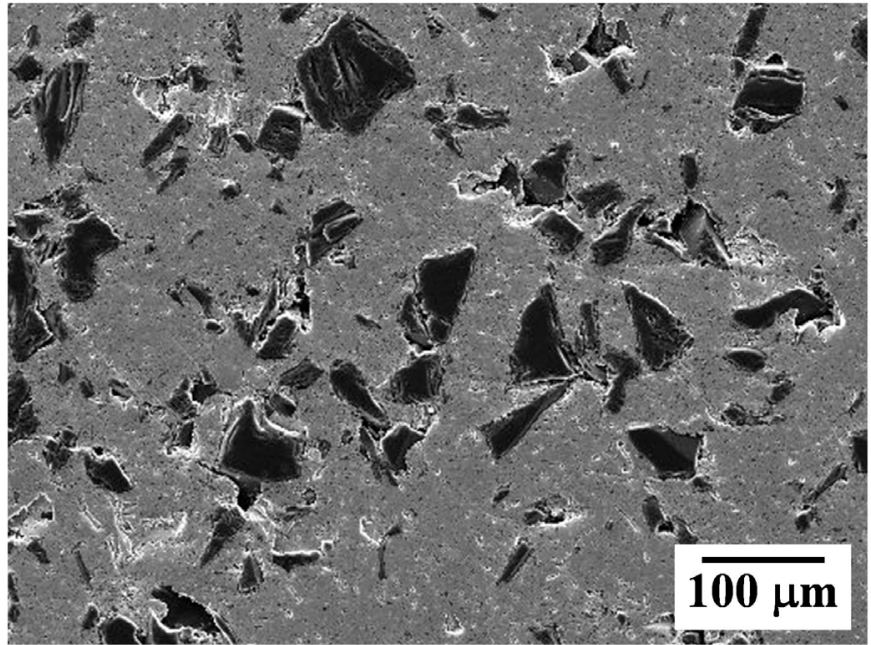

Fig. 2. Typical microstructure of sintered composite, prepared from $\mathrm{Cu}$ and PCS-coated SiC powders

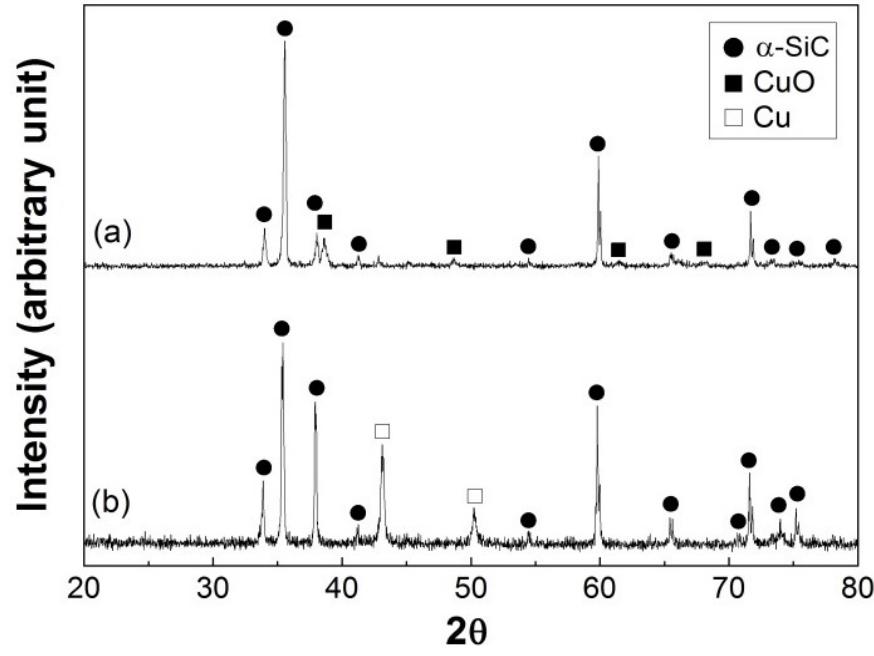

Fig. 3. XRD profiles for the powder mixtures of PCS and $\mathrm{Cu}$-nitrate coated $\mathrm{SiC}$ at different stages of processing; (a) after calcination in air at $300^{\circ} \mathrm{C}$ for $2 \mathrm{~h}$ and (b) after hydrogen reduction at $350^{\circ} \mathrm{C}$ for $1 \mathrm{~h}$ 


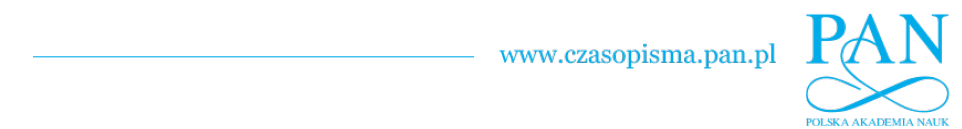

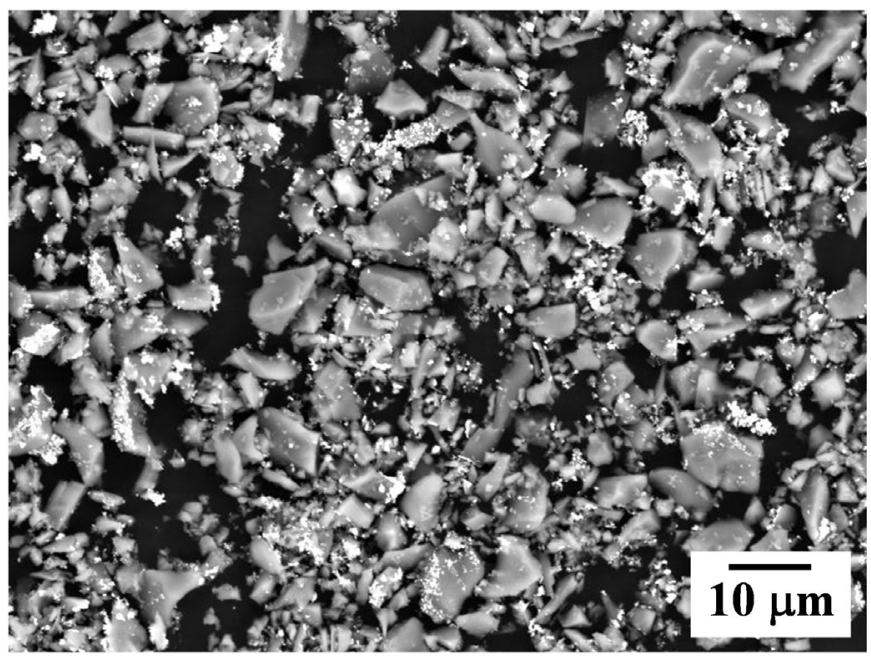

Fig. 4. Fine $\mathrm{Cu}$ particles coated $\mathrm{SiC}$ powders prepared by calcination and hydrogen reduction of $\mathrm{Cu}$-nitrate

The XRD analysis shown in Fig. 5 revealed that the observed peaks in sintered specimen were registered as a-SiC and $\mathrm{Cu}$ phase without any reaction phase in the region of its resolution. As clearly seen from Fig. 6, the sintered composite using powder mixture with $\mathrm{Cu}$-coated $\mathrm{SiC}$ showed relatively dense and homogeneous compared with that prepared by non-coated $\mathrm{SiC}$ powder (Fig. 2). For further characterization of sintered microstructure, SEM-EDX analysis was performed. As shown in Fig. 7, the sound interface between $\mathrm{SiC}$ and $\mathrm{Cu}$ phases was observed. Considering the role of coating phase in the wetting of $\mathrm{SiC}$ by $\mathrm{Cu}[11]$, therefore, it is suggested that the use of PCS and $\mathrm{Cu}$-nitrate coated $\mathrm{SiC}$ powders is one of useful approaches to fabricate the dense composite with sound microstructure.
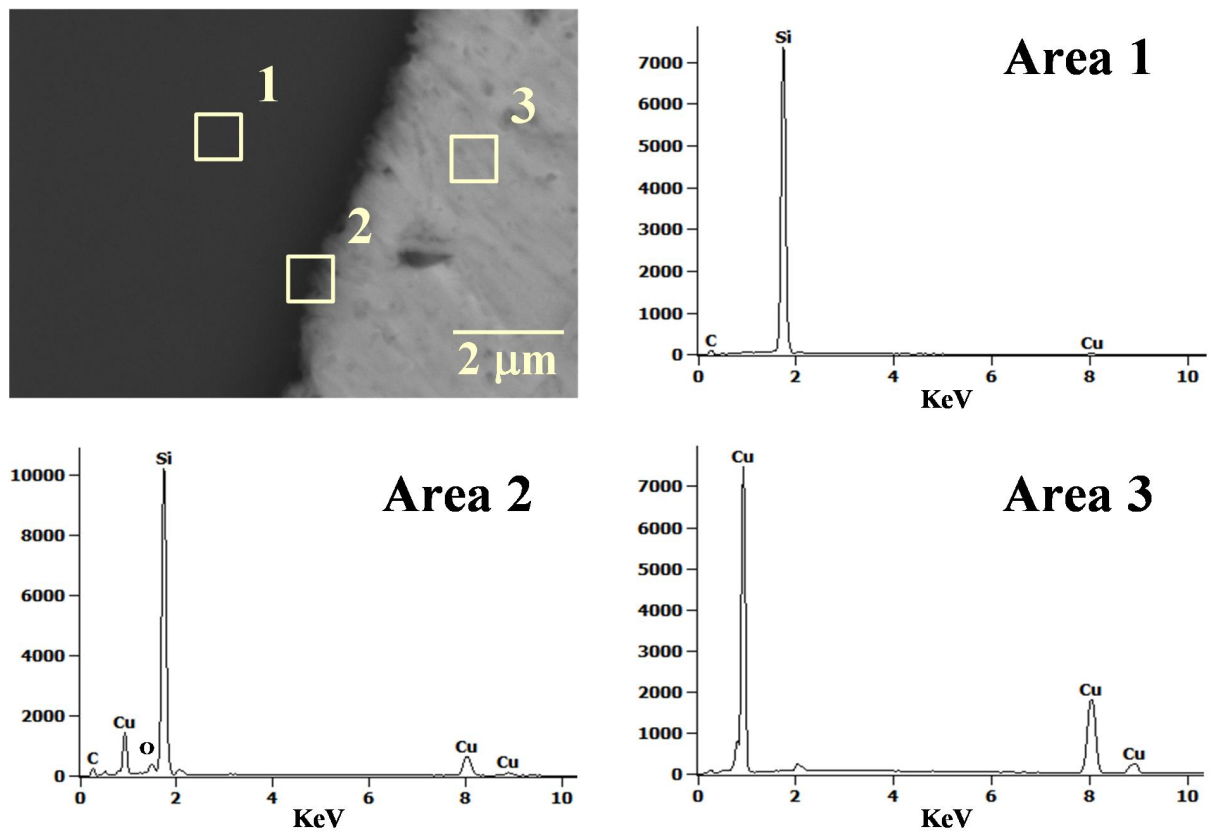

Fig. 7. Magnified image of the interface in Fig. 6 and EDX analysis for different areas 


\section{Conclusions}

Three methods for the preparation of initial powder mixture for fabrication of $\mathrm{Cu}$-based $\mathrm{SiC}$ composite have been presented and discussed on the basis of microstructural features. $\mathrm{Cu}-30$ vol\% $\mathrm{SiC}$ composite fabricated by the spark plasma sintering using $\mathrm{Cu}$ and PCS-coated $\mathrm{SiC}$ powder mixture showed dense and homogeneous microstructure compared with that using $\mathrm{Cu}$ and $\mathrm{SiC}$ powder mixture. In case of the sintered composite prepared by PCS and $\mathrm{Cu}$-nitrate coated $\mathrm{SiC}$ powder mixture, more homogeneous microstructure with sound interface between $\mathrm{Cu}$ and $\mathrm{SiC}$ phase was observed. This change in microstructure was explained by the improvement of wettability between $\mathrm{SiC}$ and $\mathrm{Cu}$ by the coating layer. These results suggest that PCS and $\mathrm{Cu}$-nitrate coating on $\mathrm{SiC}$ and further mixing of $\mathrm{Cu}$ powders as well as spark plasma sintering can provide the fabrication of the $\mathrm{Cu}$-based $\mathrm{SiC}$ composite with homogeneous microstructure.

\section{Acknowledgments}

This research was supported by Basic Science Research Program through the National Research Foundation of Korea (NRF) funded by the Ministry of Education (Grant No. NRF-2011-011811).

\section{REFERENCES}

[1] C. Zweben, JOM 50, 47-51 (1998).

[2] S.S. Sidhu, S. Kumar, A. Batish, J. Crit. Rev. Solid State Mater. Sci. 41, 132-157 (2016).

[3] A. Rape, X. Liu, A. Kulkarni, J. Singh, J. Mater. Sci. 48, 12621267 (2013)

[4] A.M. Abyzov, S.V. Kidalov, F.M. Shakhov, Appl. Therm. Eng. 48, 72-80 (2012).

[5] K.-M. Shu, G.C. Tu, Mater. Sci. Eng. A349, 236-247 (2003).

[6] S.C. Tjong, K.C. Lau, Mater. Lett. 43, 274-280 (2000).

[7] T. Schubert, B. Trindade, T. Weißgräber, B. Kieback, Mater. Sci. Eng. A475, 39-44 (2008)

[8] Y.-K. Jeong, S.-R. Bang, S.-T. Oh, J. Nanosci. Nanotechnol. 16, 1993-1995 (2016).

[9] K. Ueno, S. Kose, M. Kinoshita, J. Mater. Sci. 28, 5770-5774 (1993).

[10] J.A. Rodriguez, J.Y. Kim, J.C. Hanson, M. Pérez, A.I. Frenkel, Cataly. Lett. 85, 247-254 (2003).

[11] G. Sundberg, P. Paul, C. Sung, T. Vasilos, J. Mater. Sci. 41, 485504 (2006). 